\title{
An urban healing agenda for reform in Bahrain: where the dweller falls into the urban gap and the sailing boat hits the skyscraper
}

\author{
F. Al Khalifa \\ Department of Landscape, Sheffield University, UK
}

\begin{abstract}
The change of the Arabian Gulf cities due to the sudden development in wealth after the unearthing of oil has been a subject of curiosity and concern for many years. This paper is based on a completed master's study which investigated the effects of the discovery of oil on the urban identity of Bahrain, by examining the relationship between the old and the new in the urban fabric. The thrust of the study further focused on exploring the role of two governmental institutions, the Ministry of Culture and the University of Bahrain, in stimulating this change. Using a qualitative research approach, the study employed a number of different sources of data. The first group, including archival resources, journal and newspaper articles, in addition to the diaries and writings of Englishmen, especially those of the British advisor Sir Charles Belgrave, aimed at investigating the change in the urban fabric of Bahrain since the discovery of oil. The second group, including questionnaires and interviews, aimed at examining the consequences of this change in the work of the two governmental institutions today. The study provides a description of the change in the urban identity of Bahrain, and an understanding of how the effects of this change in shaping the lifestyle and ideologies of people living on the islands today. Some limitations in the practices of the two institutions are highlighted, and recommendations for both the Ministry of Culture and the University of Bahrain are proposed.

Keywords: urban identity, cultural change, cultural heritage, conservation, oil, Bahrain, Urbanism.
\end{abstract}




\section{Introduction}

The focus within the title of this paper, "Bahrain: where the dweller falls into the urban gap and the sailing boat hits the skyscraper", describes the problem in Bahrain today: the gap that was created after the Industrial Revolution in the urban fabric, causing segregation between the new and the old. In addition, the continued ignorance of the government to the core problem, and the repetition of the same mistakes on a daily basis, is resulting in a further widening of the urban gap. The public in Bahrain today find themselves tangled between the need to preserve the uniqueness and distinctiveness of their traditions and culture, and the urge to follow contemporary norms of modernisation.

The present study was designed to determine the effect of the discovery of oil on the urban identity of Bahrain, through a thorough investigation of the situation before and after the Industrial Revolution. It further aimed to explore the political, socio-cultural and economic mechanisms behind the on-going degradation in the relationship between the past and the present in Bahrain today by means of evaluating the role of key governmental institutions in Bahrain and their role in the continuation of the effects of the Industrial Revolution.

The aim of this research was to assess the different factors that have shaped the urban fabric of Bahrain throughout the last eighty years following the discovery of oil, to highlight the conflicts and disharmonies caused by this change in the urban identity, and to explore its effects in shaping the lifestyle and ideologies of people living on the island today.

\section{The context: this is Bahrain}

The research revolves around Bahrain (officially known as the Kingdom of Bahrain), a country in the Middle East with a total area of roughly 270 square kilometres [1]. This is less than one fifth the area of Greater London (1572 square metres) [2]. The country is an archipelago consisting of a large island

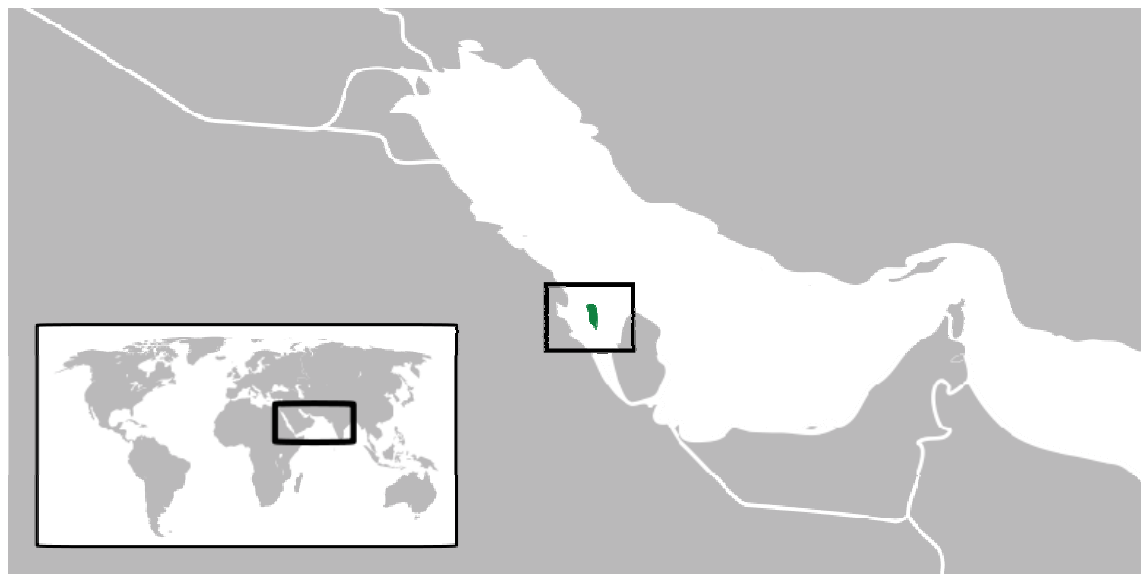

Figure 1: Bahrain's location. 
surrounded by a set of 33 smaller islands, some of which are connected to the mainland through bridges, while others are still only accessible by boat.

Saudi Arabia is connected to Bahrain by the King Fahad Causeway from the west. The state of Qatar is to the southeast of the country across the Gulf of Bahrain [3]. Bahrain's location in the Arabian/Persian Gulf played a big role in shaping its history. Due to its intermediate location between the Western and Indian sub-continents, it has been a transit point and gateway to the Arabian Gulf. This explains why it has always been subject to political and economic demands.

The culture of Bahrain is generally characterised as a Middle Eastern-Arabian Gulf culture (Khaleeji; meaning: associated with the Arab states of the Arabian Gulf). Although the main religion on the island is Islam, Bahrain is however known for its tolerance to other faiths and practices [4]. Consequently, there are many types of religious buildings, including mosques, ma'tams, churches, and temples. Arabic is the main language; however, English is widely used in most official, commercial and educational institutions, and as a second language by the general public.

Bahrain is a constitutional monarchy headed by the King, Sheikh Hamad bin Isa Al Khalifa [5]. It has a very open culture in comparison to many countries in the Arab world. There is a general respect towards women's rights; furthermore, the country gained the status of being the most prolific book publisher in the Arab world in 2005 [6].

\section{Bahrain: from desert to development}

Cities around the world witnessed vivid changes in their structure, form, and demographics following the Industrial Revolution. The anatomy of this transformation has been investigated by many scholars and researchers who are keen to learn about the transition of the world's cities from organic and traditional to modern, industrial, and functional urban forms. Furthermore, problems such as pollution, global warming, and the social and cultural degradation of cities and regions are collective consequences of the industrial boom which hit most of the world's cities and have been subject to extensive research, exploration and investigation ever since [11, 12].

Bahrain is one of the countries hit by the Industrial Revolution after the discovery of oil. The major challenge in Bahrain's case, as in many Gulf countries, was that it skipped a huge amount of natural and gradual development between the desert life existing before the discovery of oil in 1931 [13] and the Industrial Revolution afterwards, which was the extreme opposite. There was a huge jump into complete modernization in a relatively short period of time.

Prince Faisal: "No Arab loves the desert. We love water and green trees. There is nothing in the desert and no man needs nothing. Or is it that you think we are something you can play with, because we are a little people? A silly people, greedy, barbarous and cruel? What do you 
know, lieutenant? In the Arab city of Cordova, there were two miles of public lighting in the streets when London was a village" [14]. (Spoken by Alec Guinness, in the film, Lawrence of Arabia.)

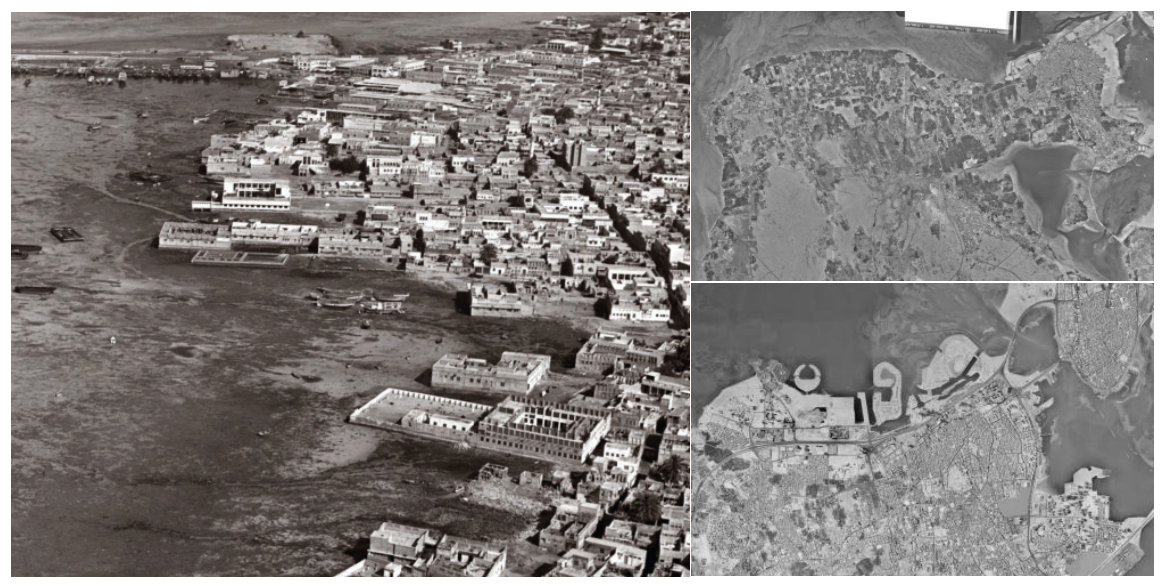

Figure 2: Historic aerial photograph of Muharraq in the 1960s (left), aerial view of Northern Bahrain (Manama) 1977 (upper right), aerial view of Northern Bahrain (Manama) 2007 (lower right) [7-9].

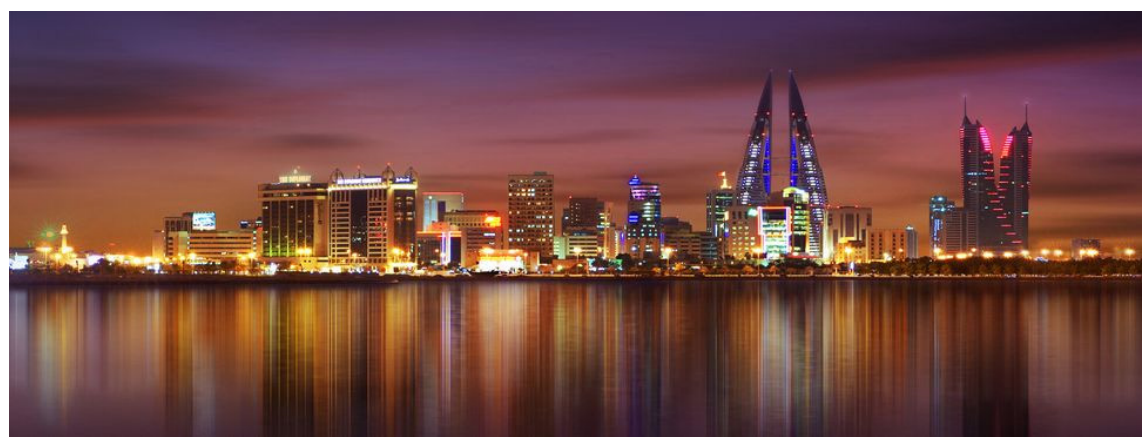

Figure 3: $\quad$ Skyline of Manama, as seen from the sea, 2011 [10].

Although the resources for reform and development were available, the local residents of Bahrain were not ready for such an extreme transformation, and did not have the expertise or capabilities needed at that time for such an alteration. Consequently, a lot of expatriates were employed to lead some of the major urban development and planning projects in Bahrain. This resulted in the creation of urban forms and spaces which are completely alien to the context, caused by foreigners' lack of understanding of local traditions and the local identity of Bahrain. An urban gap was created as a consequence, detaching the modern from the traditional. 
The change in urban identity is a phenomenon that has materialized in Bahrain during the last eighty years. Today, the magnitudes of this phenomenon are evident in the economic and environmental, but more importantly, in the social and cultural aspects of citizens' lives in Bahrain.

In 2007, the Bahraini government established criteria for its sustainable development, hoping to reverse some of the devastating consequences of the discovery of oil; the criteria were summarized in a plan to be implemented by the year 2030 [15].

Although the country progressed rapidly in ensuring economic sustainability, unfortunately things have not changed for the better in terms of social, cultural or environmental sustainability. For instance, economic reclamation projects are still taking over most of Bahrain's shoreline, destroying some important natural habitats, marine life, and cutting off public access to the coast $[16,17]$.

The Bahraini authorities seem to have become completely occupied by their new plans to provide state-of-the-art infrastructure services, housing opportunities for the underprivileged, and good conditions for investment to ensure economic sustainability and growth. However, this obsessive focus on the economy has resulted in matters of equal importance being neglected in the long term, further widening the urban gap created earlier by the extreme transformation led by foreigners in Bahrain. It is obvious today that there is segregation between the historical urban fabric and the newly-developed contemporary urbanization taking place mostly on the seashore.

The urban gap that was created after the discovery of oil and the subsequent change in the urban identity of Bahrain is today being maintained by an on-going disregard of the core problem. It is also obvious that the implementation of a fully-rounded sustainable regeneration strategy is vital for healing the gap in Bahrain's urbanism in a way that will restore its indigenous identity and revive its historic urban fabric.

\section{Methodology}

The following research questions were addressed in this study: How did the unearthing of oil affect the urban identity of Bahrain, both physically and socially? And what is the role of the government today in stimulating or preventing change in the urban identity?

The question of the effect of the discovery of oil on the urban identity focuses mainly on 'how and why' rather than 'how much' or 'how many'; therefore, this research was best explored through a qualitative approach. The purpose of this research was to implement a historical analysis of the major events and factors that shaped the urban identity of Bahrain before and after the unearthing of oil, followed by a case study examination of two governmental institutions in Bahrain today and their role in affecting the urban identity and the continuation of the phenomenon in question.

This research has been approached along four main lines of investigation. The argument was founded via a literature review that draws extensively from the concepts in question and the context in which these concepts are applied in the 
focus of this research. This argument was then followed by a critical examination of the writings and diaries of Orientalists and Englishmen, especially Belgrave's diaries, and the translation of those diaries by a number of Bahrainis. I then selected case studies to examine the conflicts between the cultural and economic models of today, and explored the political, socio-cultural and economic mechanisms behind the continuity of degradation in the relationship between the past and the present in Bahrain. Finally, questionnaires and interviews were used to understand the current situation with regards to the role of the Ministry of Culture and the University of Bahrain in the continuation of the problem. 32 responses from the questionnaires were analysed and categorised into different themes; from those themes, five participants were selected to be interviewed using an interview schedule.

\section{Urban identity in the relevant context: definition of terms}

"Identity" is a term that is used in a wide range of disciplines [18]. In the field of social sciences and particularly in social psychology, the term generally describes one's notion and manifestation of individuality or group affiliations [19]. In Webster's Ninth New Collegiate dictionary (1983), it is defined as "the distinguishing character or condition of a person or a thing" [20].

Although the term has been given a great deal of attention, there is much less agreement in the literature on how the bond between places and people should be measured and defined [21]. Place attachment, place identity, sense of place, and place dependence are all terms that describe people's bonds with places. Lynch (1981) defines identity in relation to places as "the extent to which a person can recognize or recall a place as being distinct from other places" [22].

Of the many concepts used to describe people's associations with places, two are assumed to predict people's strength of affiliation with the history of the place: place attachment and place identity [21]. Place attachment comprises three main components: behavioural, cognitive and affective [23, 24]; however, it is most frequently measured by its emotional elements [21]. As this study is focused on the built environment, the concept of place attachment will consequently not be the focus of this research.

Within the context of the Arab world, in her paper about the crises of identity in the contemporary Arab city, Sherine Aly [25] defines the term "identity" as "the foundation to place attachments and sense of belonging, it is a reflection of people's traditions, culture, aspirations, needs, and their future" [25]. Within her definition of identity, she states that it is a prerequisite to achieving place attachment.

Place identity, on the other hand, is a concept that is more connected with the material environment and is further away from the notion of subjectivity [26]. The word "identity" in this concept refers to two things: sameness (continuity) and distinctiveness (uniqueness) [21]. Place identity is also linked to the Latin term "genius loci", which is used extensively in landscape architecture to describe the character or spirit of a place [27]. 
The identity of places is therefore a feature that is not easily reducible or separable from the physical qualities of a place. It is not a constantly changing quality, and nor should it be considered constant. It is a quality that brings a sense of belonging and attachment; it connects people together. It is a dominant quality that overcomes the economic deficiency and physical decline of places [25]. Identity cannot be found, nor can it be fabricated; rather, it is an authentic process that links us to previous civilizations and nations through culture, beliefs, and traditions [28]. It is this definition of identity that is more relevant to the scope of this research, one which considers the place and physical environment as a precondition to its existence.

Now that the term "identity" has been well-defined in relation to the physical environment, it is vital to specify the nature and characteristics of that environment by directing the research to focus on one category of "spaces". This research aims to investigate the "identity" of "urban" spaces in Bahrain.

An urban area is generally characterized by a greater inhabitant density. Cities, towns and conurbations are considered as urban areas, while villages and rural areas are not [29]. Despite the general understanding of the term, different nations define the term "urban" in various ways. What is considered an urban area in some countries might not be considered so in other countries [30]. Thus, the United Nations Statistics division defined the term "urban" in the 2005 demographic yearbook for every country according to its own national definition. An urban area in Bahrain is defined using the definition of "urban" by the United Nations as "communes or villages of 2500 or more inhabitants" [31].

The "identity" of an "urban" place can now be defined as the reflection of the traditions, culture and ambitions of all the local people living in an urban area. It expresses their relevance to each other and the coming generation's (sameness: continuity) and on the other hand their uniqueness and distinctiveness from others. Although the urban space is usually understood and read through its material environment rather than the sensual, it is however the sensual environment which enables us to build memories and emotions, and create bonds with places [25].

To further properly understand the term from a historical perspective, one must note that there are theories which hypothesise how urban identities are created, most of which agree that it is created through a complex collaboration between social, built and natural components. For that reason, in trying to understand and define the urban identity of a place from a historical perspective it is essential to understand all the factors that have led to its formation, including the three components mentioned earlier, and not only the historically significant buildings in that place [20,25].

It is vital also to understand that there are other theories which carry differing associations, but are very much connected with this term. Social identity and cultural identity are directly linked to urban identity and are preconditions for it. The first describes the belonging to a precise category of ethnic group, a certain professional group, religion, nationality, or any bond that connects people together without the constraint of a place, while the second is more constrained 
by physical space and concentrates on social systems and assemblies rather than the individual's connection with others [32].

This definition of the terms in question and their associated concepts situates this research in its context and sets a framework that excludes other terms which are beyond the scope of this study.

\section{Findings and discussion}

The urban fabric of Bahrain is a physical representation of the community's beliefs and ideologies. Therefore, the change in Bahrain's urban identity after the Industrial Revolution was only a consequence of the change in society itself; its altering political system, and people's lifestyles and interests, and sources of the economy were all mirrored in the physical environment in which the society was situated.

When the community was mainly dependant on agriculture and the sea as the main source of the economy, when the social structure of the community was dominated by tribal affiliations, and the only materials for building were limestone, palm tree branches, mangroves and mud, this was reflected in the urban fabric of Bahrain, and its general identity and character echoed the sociocultural, economic and physical constraints of the society and its environment. Houses competed to be built around the coastline, palm tree farms or sweet water resources. The roads were narrow, perpendicular to the sea and used to divide tribal zones. Houses were mainly a maximum of one or two storeys high, built to respect the human scale and to adapt to the environment.

However, when black gold was discovered, things changed; the sandy narrow alleys were widened and asphalted, the houses competed to be built away from each other in urban sprawls, links with the seashore were interrupted by threelane motorways, and land reclamation further extended the distance between the original urban fabric and the sea. Harbours were filled with gigantic skyscrapers, palm tree farms were replaced by alien structures, and sweet water resources were abundant for the treated seawater. Therefore, in general, it seems that although the discovery of oil had amazing benefits for the economy of the country, it resulted in a change in Bahrain's urban identity and the loss of its unique character.

This change was not only the result of the sudden development in economic circumstances but also because of the isolation of the Gulf in general and Bahrain in particular by the British Empire after the discovery of oil. This isolation had devastating effects on the community, the government, and the cultural heritage of the country. The effects are evident today in the practices of governmental institutions, especially those responsible for the country's cultural heritage and the national legacy of previous civilisations.

One of the more significant findings to emerge from this study is that the government in Bahrain is today stimulating this change in the urban identity. This was evident in the analysed work of two institutions, the Ministry of Culture and the University of Bahrain: 
1. The Ministry of Culture, through:

- The deficiency of the framework in which the Ministry performs, which takes shape in the unsuitable and outdated law that guards Bahrain's cultural heritage and the loose implementation of the regulations in its articles.

- The lack of a proper conservation system in Bahrain.

- The absence of public participation in the heritage protection process.

- The shortage in the promotion of cultural heritage caused by the insufficient collaboration between the Ministry of Culture and the Information Authority.

- The placement of the "Al Waqf” system and its associated properties under a different guardian body which lacks the expertise and the proficiency required to deal with historic buildings.

2. The University of Bahrain, through:

- The deficiency of the current architecture curriculum that materialises in the lack of topics covering the significance of the country's cultural heritage and the importance of its preservation at both the national and international level.

- The lack of specialisation in conservation and conservation or culturalled regeneration.

- The unskillfulness of graduates from the Department of Architecture in the fields of conservation and protection of heritage, and their inappropriateness to feed into the Ministry of Culture.

Taken together, these results suggest that the urban identity of Bahrain has been changing for the last eighty years since the discovery of oil, and it is still transforming very rapidly at the expense of the unique character it used to possess, due to the deficiencies of governmental institutions.

Although the urban fabric still has some traces of previous civilisations and the normative urban form that existed before the Industrial Revolution, it however no longer has a clear identity of what it is. It seems that Bahrain is in the process of modernisation, but at the same time, it struggles to keep some aspects of the traditional. The country is finding its way into a new identity and is exploring the possibilities to settle into a new character which reflects both the significance of its history and the importance of its future.

The results of this research support the idea that there needs to be more collaboration between the governmental institutions that are responsible, either directly or indirectly, for the protection and promotion of the country's cultural heritage, in order to slow the pace of change and control the alteration and destruction of the remaining important heritage.

One possible implication of this is the possibility for the Ministry of Culture to have its own department within the Information Authority (previously ministry of information and culture), despite the recent separation of the two bodies. This will minimise the efforts needed for collaboration between the two organisations and will assist in the promotion of the country's cultural heritage and the advertisement of the Ministry’s programmes and activities. 


\section{Recommendations}

The findings of this study suggest several courses of action for both institutions, the Ministry of Culture and the University of Bahrain:

1. Recommendations for the Ministry of Culture:

- To have a proper conservation system that will ensure the protection of Bahrain's cultural heritage and its physical, social and economic sustainability in the future.

- $\quad$ To refine the law regarding the protection of Bahrain's cultural heritage according to the recommendations set out in the previous chapters.

- To collaborate with the University of Bahrain by assigning some real projects and developing programmes and activities for students of architecture to learn the conservation practice through the proficiency of the conservation team at the Ministry.

- To consider including "Waqf" properties under the umbrella of the Ministry of Culture, or at least through the collaboration with the Ministry of Justice, Islamic Affairs and Endowments.

2. Recommendations to the University of Bahrain:

- To repair the deficiency in the current curriculum of architecture, by enhancing the existing module which tackles the indigenous architecture of Bahrain, and include within its syllabus the national and international importance of the country's cultural heritage.

- To offer more often the elective module specialising in the conservation of historic buildings.

- To consider in the future having a postgraduate-level programme specialising in the conservation of historic buildings and/or conservation/cultural-led urban regeneration.

- To collaborate with the Ministry of Culture and try to educate a number of local proficient graduates to feed into the Ministry of Culture and work on the cultural heritage of the country.

\section{Conclusion}

The findings of this research add substantially to our understanding of the current urban identity of Bahrain, by comprehending the factors that shaped its transformation up until it reached its current condition. Furthermore, it grasps the importance of the Ministry of Culture and the University of Bahrain in stimulating or preventing change in the urban identity of Bahrain.

This research has thrown up many questions which are in need of further investigation; some of these will be fully addressed in a $\mathrm{PhD}$ thesis which is currently being carried out. The PhD study will cover the overall sustainability of the urban fabric of Bahrain, including the socio-cultural, economic and environmental aspects. Hence, the findings discussed in this paper will feed into one central part of the PhD study, which aims to study the use of the existing heritage and the respect of the urban identity of the country in the regeneration 
process, to ensure the continuity of the culture, character, and uniqueness of Bahrain cities throughout future urban renewal projects.

Considerably more work will need to be done to draft a proper listing system that suits the context of Bahrain and the community in which this system will be applied. Future research should therefore concentrate on a new law for the protection of the country's cultural heritage.

It would be interesting to compare the traditional "Waqf” Islamic endowment system with the modern western conservation system, in an attempt to draft principles for a conservation practice which is more appropriate for application in the Arab-Islamic region today, instead of the adaptation of other nations' practices and systems.

More importantly, what is now needed is a cross-organisational study involving collaboration between different governmental institutions and the formation of joint projects and programmes to safeguard Bahrain's cultural heritage and spread awareness among the public of its importance.

\section{References}

[1] Gugger, H., Bahrain lessons, Laboratoire de la production d'architecture, 2010.

[2] Wikipedia, Greater London, http://en.wikipedia.org/wiki/Greater_London.

[3] Wikipedia, Bahrain, http://en.wikipedia.org/wiki/Bahrain.

[4] Ministry of Foreign Affairs, Ambassador Houda Nonoo highlights religious freedom in Bahrain, Bahrain, http://www.mofa.gov.bh/Default.aspx? tabid=7824andlanguage=en-USandItemId=1549.

[5] Bassiouni, M. C., Report of the Bahrain Independent Commission of Inquiry. Bahrain Independent Commission of Inquiry, 2011.

[6] Toumi, H., Bahrain tops publishing sector among Arab states. Gulf News: Al Nisr Publishing, 2006.

[7] Ministry of Culture, Pearling: testimony of an island economy, 2010.

[8] Ministry of Culture, Aerial View of Manama 1977, 2011.

[9] Ministry of Culture, Aerial View of Manama 2007, 2011.

[10] Bahrain Economic Development Board, Skyline of Manama, 2011.

[11] Sexton, T., The Impact of the Industrial Revolution on Urban Life, http://voices.yahoo.com/the-impact-industrial-revolution-urban-life1806379.html.

[12] LeGates, R. T. and Stout, F., The City Reader, Fifth Edition. New York: Routledge, 2011.

[13] Oxford Business Group, The Report: Bahrain, 2009.

[14] Lean, D., Lawrence of Arabia (written by Robert Bolt and Michael Wilson), Horizon Pictures, 1962.

[15] Skidmore, O. and M., Bahrain National Planning Development Strategy 2030, Bahrain Economic Development Board, 2007.

[16] Ministry of Culture, RECLAIM: Kingdom of Bahrain National Participation in Venice Biennale 2010, Manama, 2010. 
[17] Al Ansari, F., Public Open Space on the Transforming Urban Waterfronts of Bahrain: The Case of Manama City, University of Newcastle, 2009.

[18] Baris, M. E., Uckac, L., and Uslu, A., Exploring public perception of urban identity: The case of Ankara. African Journal of Agricultural Research, 4(8), pp. 724-735, 2009.

[19] Wikipedia, Identity (social science), http://en.wikipedia.org/wiki/Identity_ (social_science).

[20] Oktay, D., The quest for urban identity in the changing context of the city. Cities, 19(4), pp. 261-271, 2002.

[21] Lewicka, M., Place attachment, place identity, and place memory: Restoring the forgotten city past. Journal of Environmental Psychology, 28(3), pp. 209-231, 2008.

[22] Lynch, K., A Theory of Good City Form. MIT Press: Cambridge, 1981.

[23] Jorgensen, B. S. and Stedman, R. C., Sense of place as an attitude: Lakeshore owners' attitudes toward their properties. Journal of Environmental Psychology, 21(3), pp. 233-248, 2001.

[24] Kyle, G. T., Mowen, A. J., and Tarrant, M., Linking place preferences with place meaning: An examination of the relationship between place motivation and place attachment. Journal of Environmental Psychology, 24(4), pp. 439-454, 2004.

[25] Aly, S. S. A., Modernization and regionalism: Approaches for sustainable revival of local urban identity, 2011 International Conference on Green Buildings and Sustainable Cities, 21, pp. 503-512, 2011.

[26] Dixon, J. and Durrheim, K., Dislocating identity: Desegregation and the transformation of place. Journal of Environmental Psychology, 24(4) pp. 455-473, 2004.

[27] Wikipedia, Genius loci, http://en.wikipedia.org/wiki/Genius_loci\#Art_ and_architecture.

[28] Abel, C., Architecture and Identity: Towards a Global Eco-culture. Architectural Press: Oxford, 1996.

[29] Wikipedia, Urban area, http://en.wikipedia.org/wiki/Urban_area.

[30] United Nations, Table 6: Urban and total population by sex: 1996-2005, Demographic Yearbook, 2005.

[31] United Nations, Definition of urban, Demographic Yearbook, 2005.

[32] Twigger-Ross, C. and Uzzel, D. L. Place and identity processes. Journal of Environmental Psychology, 16(3), pp. 205-220, 1996. 